\title{
Diagnóstico de psicopatia: a avaliação psicológica no âmbito judicial
}

\author{
Rodolfo Augusto Matteo Ambiel
}

\section{Hare, R. D. (2004). Manual Escala Hare PCL - R: critérios para pontuação de psicopatia - revisados.} Versão brasileira: Hilda Morana. São Paulo: Casa do Psicólogo.

No Brasil, estima-se que a reincidência criminal esteja na casa dos $80 \%$. O número, que por si só pode ser considerado alarmante, leva a pensar, entre outras coisas, sobre a questão da superlotação das cadeias. Dessa forma, o problema tende a aumentar cada vez mais, já que, além dos novos presidiários que chegam ao sistema a cada ano, pode-se esperar que uma parcela muito grande daqueles que saem voltem aos presídios. Assim, o sistema penal, que já não cumpre devidamente seu papel de recuperar os indivíduos em falta com a lei, pode oferecer cada vez menos soluções e mais problemas à sociedade como um todo.

Além de se pensar na questão institucional, deve-se pensar sobre os presidiários, usuários da instituição. A lei que rege o Sistema Penal Brasileiro prevê um caminho progressivo que o presidiário pode vir a percorrer, iniciando no regime fechado, passando posteriormente ao semi-aberto e, finalmente, chegando ao regime aberto. Além disso, alguns benefícios, como indultos e comutação de pena, podem ser concedidos aos encarcerados, dependendo de resultados de exames e perícias. Entretanto, é importante observar que, com um índice tão alto de reincidência criminal, as decisões sobre a liberação dos presos, seja por meio da progressão, seja por meio de benefícios, são de extrema importância e devem ser baseadas em instrumentos confiáveis, que tenham a capacidade de diagnosticar comportamentos que indiquem possibilidade de reincidência, evidenciando estruturas de personalidade que possam trazer algum grau de perigo à sociedade.

Nesse sentido, a escala PCL - R (Psychopathy Checklist Revised), de autoria de Robert D. Hare, foi tema da tese de doutorado da psiquiatra Hilda Morana, defendido na Faculdade de Medicina da Universidade de São Paulo. No trabalho, a autora buscou identificar o ponto de corte da versão brasileira, ou seja, a partir de que pontuação um sujeito pode ser considerado psicopata, tornando a escala apta para utilização em contexto nacional, sendo sua venda recentemente permitida pelo Conselho Federal de Psicologia (CFP).

$\mathrm{O}$ PCL - R, que é o primeiro exame padronizado exclusivo para o uso no sistema penal do Brasil, pretende avaliar a personalidade do preso e prever a reincidência criminal, buscando separar os bandidos comuns dos psicopatas. A autora defende em sua tese que não é o tipo de crime que define a probabilidade de reincidência, e sim a personalidade de quem o comete. Assim, os estudos visando à adaptação e validação desse instrumento para a população forense brasileira, bem como sua comercialização para os profissionais da área, há muito urgiam ser viabilizados no Brasil.

A questão da psicopatia ainda é um tanto controversa, já que há tempos existe a discussão se tal patologia, enquanto perturbação da personalidade, deve ser considerada como uma categoria diagnóstica nas classificações internacionais ou se os transtornos de personalidade já catalogados dão conta de identificar os sujeitos que apresentam tais distúrbios de conduta. Atualmente, é usada a denominação transtorno antissocial da personalidade, mas estudos recentes, inclusive da própria autora, mostraram a necessidade de se diferenciar dois subtipos dentro dessa classificação, a saber, transtorno parcial da personalidade, menos grave e que geralmente caracteriza os ditos criminosos comuns, e transtorno global da personalidade, que se aproxima do conceito de psicopatia de Hare.

A psicopatia é entendida atualmente no meio forense como um grupo de traços ou alterações de conduta em sujeitos com tendência ativa do comportamento, tais como avidez por estímulos, delinqüência juvenil, descontroles comportamentais, reincidência criminal, entre outros. É considerada como a mais grave alteração de personalidade, uma vez que os indivíduos caracterizados por essa patologia são responsáveis pela maioria dos crimes violentos, cometem vários tipos de crime com maior freqüência do que os não-psicopatas e, ainda, têm os maiores índices de reincidência apresentados.

Assim, o que o PCL - R pretende diferenciar são os psicopatas dos não-psicopatas, segundo a proposta de Hare. Um dos principais objetivos da escala é identificar os sujeitos com maior probabilidade de reincidência criminal, sendo assim, além de um instrumento diagnóstico importante para tomada de decisão acerca do trâmite do condenado no sistema penal, uma ferramenta para separar os que apresentam tal condição daqueles que não a apresentam, com vistas a não prejudicar a reabilitação dos chamados criminosos comuns.

\footnotetext{
${ }^{1}$ Endereço para correspondência:

E-mail: ambielram@yahoo.com.br
} 
Amparado por um material de excelente qualidade gráfica, o profissional que fizer uso do PCL $\mathrm{R}$ contará com um manual que contém todas as informações necessárias para o bom uso do instrumento. $\mathrm{Na}$ primeira parte, a autora traz os estudos realizados detalhando a amostra, que contou apenas com adultos do sexo masculino, fato que não restringe o uso a populações de mulheres presas, uma vez que o próprio Hare fez estudos demonstrando não haver diferenças significativas entre gênero, e os estudos estatísticos que determinaram o ponto de corte. Para confirmar essa pontuação, que na padronização brasileira ficou em 23 pontos dentre os 40 possíveis na escala, a autora lançou mão das pranchas de Rorschach como critério externo na identificação de sujeitos que apresentem traços psicopáticos, ou de transtorno global da personalidade, conforme a identificação do referido teste projetivo.

As análises estatísticas mostraram que o PCL $\mathrm{R}$ é capaz de distinguir os indivíduos que apresentam traços prototípicos de psicopatias, ou transtorno global da personalidade, daqueles que apresentam traços de transtorno parcial da personalidade, menos graves, e, ainda, estes do grupo de controle, que não apresentam qualquer tipo de desvio de conduta. Esses resultados foram corroborados pela prova de Rorschach, segundo a avaliação de vários especialistas, demonstrando a concordância por meio do índice Kappa de 0,83.

$\mathrm{Na}$ segunda parte do manual, a autora inicia o primeiro capítulo fazendo uma revisão histórica, tanto do instrumento, que teve sua primeira versão em 1980, quanto do construto de psicopatia. Em seguida, faz uma descrição dos materiais que compõem o instrumento, a saber, manual técnico, caderno de pontuação, roteiro para entrevista semi-estruturada e protocolo de pontuação, além de trazer todas as especificações para se fazer o melhor uso possível do instrumento, uma vez que, como Morana destaca, a obtenção errônea de escores como resultado de má utilização desse ou de qualquer outro instrumento de avaliação psicológica pode levar a prejuízos imediatos e futuros para o indivíduo avaliado.
Ainda no segundo capítulo da segunda parte do manual, os itens do protocolo e suas interpretações são descritos e discutidos, visando a um melhor proveito das informações obtidas nas entrevistas. É importante dizer que o Caderno de Pontuação que completa o material é, na verdade, uma reprodução desse segundo capítulo, porém de uma forma que facilita o acesso às descrições dos itens, objetivando mais segurança e confiabilidade na avaliação.

Nos demais capítulos, são apresentados vários estudos psicométricos do instrumento, conduzidos por Hare e colaboradores nos Estados Unidos e Canadá, numa população total de 1.632 sujeitos. São relatados estudos de precisão entre avaliadores, interitem, testereteste e consistência interna, que, na maioria dos casos, mostraram bons índices, indicando que $\mathrm{O}$ instrumento conta com boa fidedignidade. Além desses, estudos de validade de conteúdo, critério e construto também são apresentados, demonstrando índices altos. No futuro, estudos como esses, realizados por Hare e sua equipe no exterior, devem ser realizados também no Brasil, proporcionando um aprimoramento das qualidades psicométricas da versão brasileira do instrumento.

Por seu pioneirismo, o PCL - R vem ao encontro da necessidade dos profissionais brasileiros, que têm à disposição um bom material, com revisões teóricas bastante pertinentes, embora sejam necessários conhecimentos consideráveis em psicometria e estatística para fazer bom uso dos estudos quantitativos apresentados no manual. Em virtude da importância social que os instrumentos de avaliação psicológica têm, a disponibilização desse instrumento para os profissionais das áreas de psicologia e psiquiatria forense se faz de grande utilidade para avaliação da personalidade de criminosos, área em que a psicologia tem tanto a contribuir e a crescer.

Recebido em maio de 2006 Reformulado em outubro de 2006 Aprovado em outubro de 2006

\section{Sobre o autor:}

Rodolfo Augusto Matteo Ambiel é acadêmico do Curso de Psicologia da Universidade São Francisco e bolsista de Iniciação Científica PIBIC/CNPq. 